\title{
Facial Pain, CTCAE
}

National Cancer Institute

\section{Source}

National Cancer Institute. Facial Pain, CT CAE. NCI Thesaurus. Code C143474.

A disorder characterized by a sensation of marked discomfort in the face. 